\title{
Technological Embedding, Industrial Integration, Industrial Upgrading----Discuss about the Role of Information Technology in Industrial Upgrading and Transformation
}

\author{
Lin Xue-jun ${ }^{1}$, Lv Han ${ }^{2}$, Hao $\mathrm{Luo}^{3} \& \mathrm{He} \mathrm{Nie}^{2}$ \\ ${ }^{1}$ International Business School, Jinan University, Zhuhai, China \\ ${ }^{2}$ College of Economics, Jinan University, Guangzhou, China \\ ${ }^{3}$ Electrical and Information School, Jinan University, Zhuhai, China \\ Correspondence: Lin Xue-jun, International Business School, Jinan University, 519070, Zhuhai, China. E-mail: \\ tlxj@jnu.edu.cn
}

Received: November 14, 2015

Accepted: December 22, $2015 \quad$ Online Published: January 25, 2016

doi:10.5539/ijef.v8n2p39

URL: http://dx.doi.org/10.5539/ijef.v8n2p39

\begin{abstract}
At present, transformation and upgrading traditional industries are key to our country's economic development. Discussion on how to transform traditional industries utilizing the information technology is hot in academic world. Transformation of traditional industries using information technology can fall into three categories: total Integration, embedded Integration, and general Integration. The result is to form a new industry, transform traditional industries, or increase the original industry productivity respectively. German industry version 4.0 is a case in point of industry Integration through intelligent factories, smart production, intelligent network, intelligent service etc. to build a smart manufacturing industry. China should vigorously utilize "Internet + " to upgrade China's manufacturing industry, through which intelligent factories improve enterprise's productivity, intelligent production increases the productivity of the industry, intelligent network improves the productivity of the whole society, intelligent service improves the economic vitality of the whole society, hence build the Chinese industry version 4.0.
\end{abstract}

Keywords: internet + , industrial integration, transformation and upgrading, industry version 4.0

\section{Introduction}

In recent years, the upgrading of industrial transformation is a concern. Especially in China, our country is a manufacturing power, but not a manufacturing powerhouse. During the period of reform and opening-up, China has achieved rapid economic growth by developing the labor-intensive industry using the resource of cheap labors and unused lands. Today, demographic dividend has disappeared, land resources have dried up, and it's an unsustainable method to walk the original path again, therefore, the transformation of the mode of economic growth and improve the labor productivity has become imminent. Some cities put forward the slogan of "empty the cage and switch the bird", the cage was emptied, and the birds did not change, though. With the traditional industries that once had advantages in development abandoned and the emerging industries not yet developed, local industries became vacant or even dragging the economy's developing. Thus, the development of emerging industries, dose not equal to abandoning the traditional industry, on the contrary, the country should strengthen the upgrading of traditional industries, switch our country from a manufacturer into a manufacturing power.

Currently, cloud computing, Internet of things, big data and the mobile Internet such new technologies and modules are developing rapidly. Industrial and commercial internets and the intelligent manufacturing are to promote a new round of industrial revolution. Also with the "Internet +" economy rising, the informational industries' accelerating development has provided new path and motivation to the transformation of economic development patterns and transformation and the upgrading of traditional industries provides.

This essay aims at studying the informational technology industries' upgrading result on traditional industries, analyzing the system where the informational technologies use the embedding and fusing method to improve traditional industries' production rate. Then it analyzes informational technologies' fusion effect on the traditional industries by referring to the German Industry 4.0, and puts forward a political method: strongly 
develop the informational industries in order to promote its switching and fusing and therefore transform the traditional industries.

\section{Literature Review}

\subsection{Concept of Industrial Integration}

Japanese scholars Masu Uekusa (Grass profit, 1988) thinks that industrial integration meant a phenomenon where products that originally belong to different industries or market makes the enterprises in two industries or markets to compete with each other, due to the mutual substitution relationships created by technical innovation. American scholar Griess and Hannah (Greenstein \& Khanna, 1997) points out: "industrial integration as a kind of economic phenomenon is to point to in order to adapt to the growth of industry boundary shrink or disappear." This article refers to industrial integration implication, the active penetration of traditional industry, information industry fully integrated two industries, or to transform the traditional industries, improve the productivity of the traditional industry.

\subsection{Form of Industrial Integration}

According to the fusion depth and breadth of industry integration can be divided into three types: total integration, embedded integration and general integration. In the past few decades, information technology (IT) the impact on the productivity has been widely studied. Some experts and scholars are to study the effect of information technology on a country's productivity. For example: the productivity of the USA during the $1970 \mathrm{~s}$ to $1980 \mathrm{~s}$ was stagnation and later rose in the $1990 \mathrm{~s}$ relatively higher due to the large number of investment in information technology (Oliner \& Sichel, 2000; Stiroh, 2002). Some researches focused on how to use information technology to make the enterprise production and management more efficient (Brynjolfsson \& Hitt, 1996, 2003; Bloom et al., 2012). Combine all the views of experts and scholars at home and abroad, the transformation and upgrading information industry does to other industries can be divided into total integration, embedded integration and general integration.

Computers science, communications, radio and television industry integrating and forming the Internet industry, electronic network technology industry and the general business activities combining and forming a new e-commerce industry, these two examples belong to the total integration.

In terms of embedded integration, the emphasis is on information technology's completely breaking the original industry from production to marketing management, integrating into all aspects of the original industry and promoting the industry upgrading. Recent empirical and theoretical researches (Hobijn \& Jovanovic, 2001; Garleanu et al., 2012 a, b; Bartelsman, 2013; Kogan \& Papanikolaou, 2013, 2014) emphasized the information industry breaking the traditional industries' normal rule, embedding new technologies to it and leading it into innovation. For example, in the early 1990s the emergence of enterprises equipped with new digital technology in the photography industry increased with the new company to enter the industry of new technology. The new technology transformed the industry from the chemical technological to digital technological. New enterprises with digital technology challenge the traditional technology and old knowledge enterprises on the market (Benner, 2007), therefore forming the performance gap between new enterprises and old enterprises performance. Performance gap leads to the redistribution of resources, more resources flow from poor performance enterprises to high performance enterprises, therefore improve long-term productivity levels of the whole industry. As for the communication industry, the original analog signal transformed into digital signal, which had faster transmission speed, more transmission information, better and stronger anti-interference ability. These are all great examples of the information technology being embedded into the traditional industries and transforming them.

In terms of general integration, it's mainly about information technology being combined with the company's management, marketing, etc., and promoting the company's management level. Wal-Mart (Wal-Mart), for example, uses the information technology to establish a highly efficient logistics system, including the just-in-time inventory management system, which greatly improves the management level of the enterprise, enables Wal-Mart to open a shop in areas ignored by its rivals. Kmart is the dominant discount retailer in the United States in the 1980 $\mathrm{s}$, but the operation and management of the gap between Wal-Mart and Kmart began to emerge in the early $1990 \mathrm{~s}$, the gap was growing bigger, finally Kmart filed for bankruptcy in 2002 (Hyunbae, 2015). This example shows, information technology has changed the traditional business improving the operational profits of the business. 


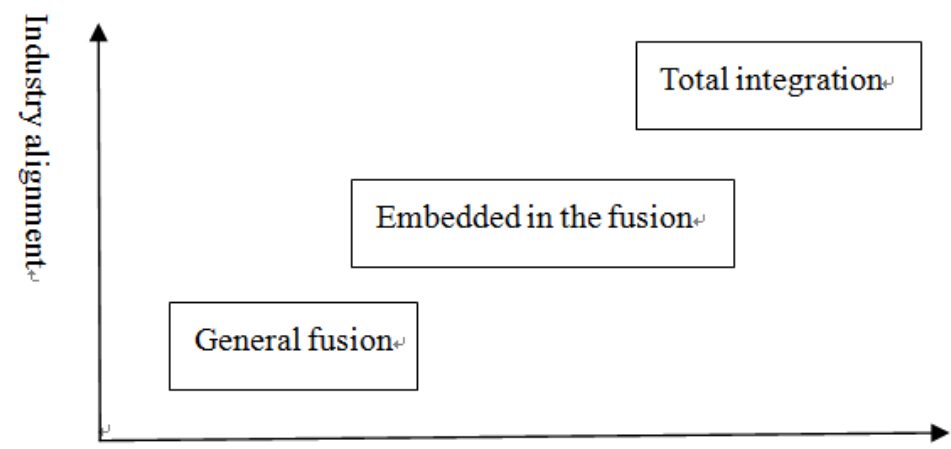

Industrial upgrading

Figure 1. The relationship between the industrial upgrading in the form of industrial integration

Industrial integration is not a simple or easy task. The traditional industries have experienced over dozens or even hundreds of years of development, and formed inherent technology, equipment, concept, operational patterns and rules of management. If you wished to introduce new technology to the industry, giving up on the old technology is inevitable. You'll have to abandon the old equipment, change the old ideas, adopt new business model and management system, these will bring additional cost of capital and human resource, so the problem of path dependence exists. However, without transforming and upgrading, sustainable development is impossible, therefore, to overcome dependence, an industry has to make technical innovation, organization innovation, management innovation, business process reengineering. Only one of these can it promote the fusion of information industry and traditional industry. The more deeply and strongly the innovation was made, the greater the reform will be (Hu Wei, 2006).

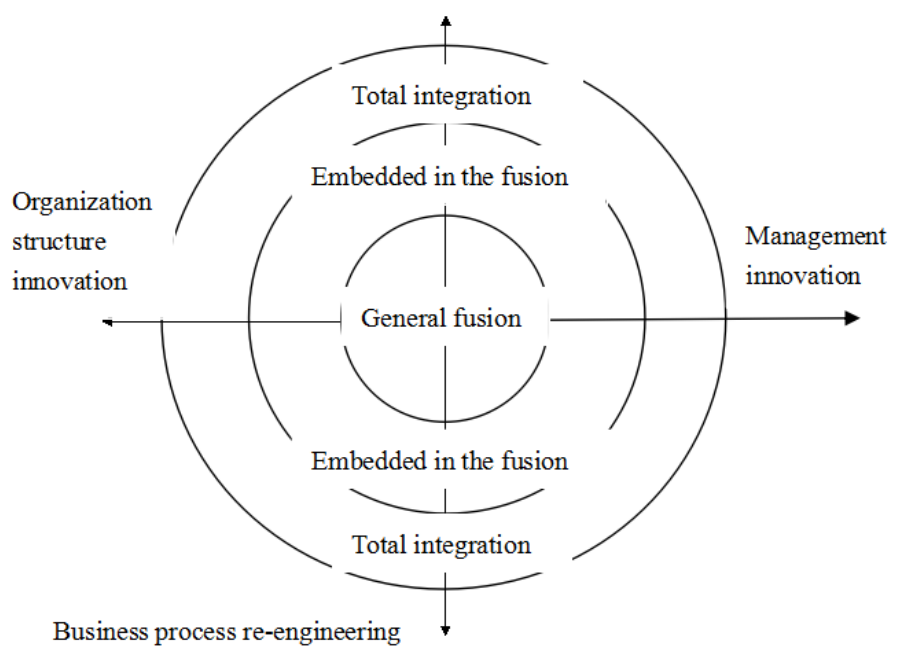

Figure 2. Industry integration and innovation

\subsection{Evaluation Index of Industrial Alignment}

In order to measure the degree of integration of information industry and traditional industry, experts and scholars have adopted some indexes (Fuxiang \& Lei, 2011). The first one is: industrial structure transformation value index. This index is during the reporting period and base period of a certain region or city information industry in the region or city the change of the proportion of all industry, from static to observe the upgrading of industrial structure changes.

The computation formula is: $K, K$ is the transformation of industrial structure, the composing ratio of the $i$-th kind of industrial structure and employment structure during the reporting period, and composing ratio of the $i$-th kind of industrial structure during the industrial base period, $n$ is the number of all industries in the region or city.

The second is structure entropy index (SEI), you can calculate the proportion of added value and employment of 
information industry of the index and observe the speed of industrial structure transformation dynamically

The Computation formula is: $E I=E I$ is the index of structure entropy, $S i$ is the industrial added value and employment proportion, $n$ is the number of all industries in the region or city.

And the third is Moore structure conversion value, using the index to explain the increase of the information industry structure to other industry's leading and spillover effects.

The calculation formula is: which said the $t$ period the proportion of kinds of industries, $i$ said the $t+1$ period the proportion of kinds of industries, $n$ is the number of all industries in the region or city. It is believed that the Angle between the molar conversions, when Moore structure conversion value decrease or Angle increase, and the industry of the corresponding boundary represented by share will increase.

\section{Experience of German Industry 4.0}

For a long time, Germany focus greatly on the integration of the information industry and manufacturing, which is an important reason why the German manufacturing remain competitive in the world. Mr Rees, etc (Voudouris et al., 2012) pointed out that in the new round of industrial revolution and the new environment where the information technology is developing rapidly, Germany will actively apply the advanced information technology to machinery and equipment manufacturing industry, and obtained remarkable achievement in the field of embedded system and automation engineering,. German academia and industry generally believe that it has dawned on the "industrial 4.0" era where information technology and industrial manufacturing are integrated. Gruber (2013) pointed out that industrial 4.0 is a new round of revolution in industrial production mode. Ever since the first automatic mechanical loom, the first waterline and the first PLC, these new technologies of the Internet, big data, cloud computing, internet of things, etc. have brought revolutionary changes to the industrial production The academia defines mechanization, electrification and informatization respectively as the industry 1.0, industry 2.0 and industry 3.0. Then this great industrial revolution of information technology and traditional industry's integrating could be defined as the industry 4.0. This industry 4.0 strategy means the fourth industrial revolution, or rather a revolutionary production method, oriented by intelligent manufacturing. This strategy aims to intelligentize the manufacturing using information communication technologies and "internet+"physical systems. Lasi et al. (2014) pointed out that this strategy is formed by German academia and manufacturing industry's active suggestions and promotions, and then soon be accepted by German government and prioritized as national strategy.

German information technology and the traditional manufacturing industry's integration can be generalized as: intelligent manufacturing, intelligent factory, intelligent network and intelligent service. The intelligent factories are described by Sailer (2014) as the German industry 4.0 strategy's information physical system including the intelligent machines, storing systems and manufacturing facilities. These systems could automatically transit information, trigger actions and controls in every segment of manufacturing such as inbound logistics, production, sale outbound logistics and services, and achieve digitalization and End to end integration. The intelligent factories make enterprises use as much intelligent robots, programmable intelligent production equipment as possible, reduce human powers and workers' labor intensity, lower energy cost and pollution, improve work efficiency and products' quality, avoid unqualified products and waste and then ultimately lower cost and improve economy benefits.

Intelligent manufacturing basically includes an enterprise's whole production logistics, human-machine interact and 3d technology's application (Industry working group, 2013). It requires dynamical management of the manufacturing process based on different aspects of the process. For example, automatically managing the production workflow, intelligently controlling production numbers and quality, logically managing production time and schedule, ensure production safety, save energy and reduce emission according to the market needs. The resources and spare parts' supply can achieve self-adjust, making the manufacturing process more adjustable, production techniques more delicate, products supplying more punctual. Also, it could adjust the production in time according to the market supply and need situations, achieving customized and personalized intelligent manufacturing. Therefore the resources are well used and more personalized services are provided to the customers and market opportunities are broadened.

Intelligent internet, as $\mathrm{Xu} \mathrm{Li}$ (2014) pointed out, German industry 4.0's intelligent network consists of these three aspects: 1). Vertical integration, which means integrating the equipment and the manufacturing system and performance system, and it, uses the internet of things and information physics. 2). Combination of every segment of a products lifespan using network technology, including designs, production, logistics, sale and after-sale services. 3). Combine all the partners using the "internet+", such as the suppliers, producers, agencies and customers. All of the above would form an intelligent network with unobstructed supply and sale information and 
keen reactions.

The intelligent service is a brand new commerce pattern developed by the German industry 4.0. These patterns could effectively satisfy customers' personalized need and is beneficial to medium or small sized enterprises' capital and technology shortage. Some of these enterprises are not capable of independently shouldering information services and the software system, but they could use this commerce pattern to innovate, start new enterprise and operate their own business. This brand new commerce pattern is beneficial for enterprises to thoroughly understand the customers and rivals, to set competition strategy for itself and to look for partners with efficient work plans. With the technology and information shared between partners and the fair competition promoted, the whole industry's labor productivity could be improved.

\section{Industrial Integration Empirical Analysis}

In order to prove the information technology industry's promotion on other industries, this article would use the gray-relation in the quantitative empirical analysis. It will begin in the following three aspects.

\subsection{Grey Management Principle}

The Grey System Theory (Ju-long, 2005) uses partial known information, partial unknown information, small samples, poor information and uncertain System as the research object, the analysis of the known information system as an effective control method. Information industry and other industries' relation could be seen as a complex system, with obvious Grey System features, so it could be analyzed with the Grey System Theory. First, we have to set reference sequence and comparison sequence, then normalize it, at last calculate the Grey Relation parameters and add in power weight to calculate the relation between the reference sequence and the comparison sequence. If the Grey relation parameters are relatively high, then the trend of these two could be seen as consistent.

The analysis data used in the article are from the Guangdong Province statistical yearbook 2001-2003, such as the information technology industries' increment, communication increment, commerce increment, real estate increment and economy increment.

\subsection{Analysis of the Grey Correlation}

\subsubsection{To Establish the Reference Sequence and Compared Sequence}

With information added value for the reference sequence, i.e. $\left\{x_{0}(t)\right\}=\left\{x_{01}, x_{02}, \ldots x_{0 n}\right\}, x_{0}$ said the added value of information, $i$ is one of the $n$ among them.

The added value of information industry and other industries form the matrix $m \cdot n$, namely:

$$
\left\{x_{1}(t), x_{2}(t), \cdots, x_{m}(t)\right\}=\left[\begin{array}{ccccc}
x_{11} x_{12} & \cdots & x_{1 n} & & \\
x_{21} x_{22} & \cdots & x_{2 n} & \\
\vdots & \vdots & & \vdots & \vdots \\
x_{m 1} x_{m 2} & \cdots & x_{m n} &
\end{array}\right]
$$

Where $n=14$ means the 13-year data used in this research, $\mathrm{m}=6$ means there are 5 more industry data other than the information industry.

\subsubsection{Unified Series}

Due to the industrial added value of orders of magnitude greater differentiation, in order to strengthen the proximity between the variables, enhance comparability, unified series of data processing, the value of every period will compare sequence and the reference sequence corresponds to the absolute value of the numerical difference to remember:

$$
\Delta_{01}(t)=\left|x_{i}(t)-x_{0}(t)\right|
$$

Among them, and at this time, $t=1,2, \cdots n, i=1,2,3, \cdots m$

$\Delta_{01}(t), \Delta_{02}(t), \cdots \Delta_{0 m}(t)$ constitute matrix $m \cdot n$.

In find the biggest difference sequence $\Delta \max =\max _{i} \max _{t} \Delta_{i}(t)$, and the least of sequence $\Delta \min =\min _{i} \min _{t} \Delta_{i}(t)$ is very poor. 
Compare the $i$-th a sequence and the reference sequence in $t$ time correlation coefficient can be expressed as:

$$
r\left(x_{0}(k), x_{i}(k)\right)=\min _{i} \min _{k} \Delta_{i}(k)+\xi \max _{i} \max _{k} \Delta_{i} / \Delta_{i}(k)+\xi \max _{i} \max _{k} \Delta_{i}(k)
$$

To distinguish coefficient $\xi$, which is used to reduce $\Delta \max$ because of too much cause the influence of the correlation coefficient of distortion, and then improve the correlation coefficient between the significance, general $\xi=0.5$.

As comparison and reference sequences of degree coefficient is through the management of management, information is scattered inconvenience from the overall grasp, therefore to the correlation information do centralized processing, and calculation formula is:

$$
\left\{x_{0}(t)\right\}=\left\{x_{01}, x_{02}, \ldots x_{0 n}\right\}
$$

Eventually get correlation as shown below:

$$
r\left(x_{0}, x_{i}\right)=1 / n \sum_{t=1}^{n} r\left(x_{0}(t), x_{i}(t)\right), i=1,2,3, \cdots m
$$

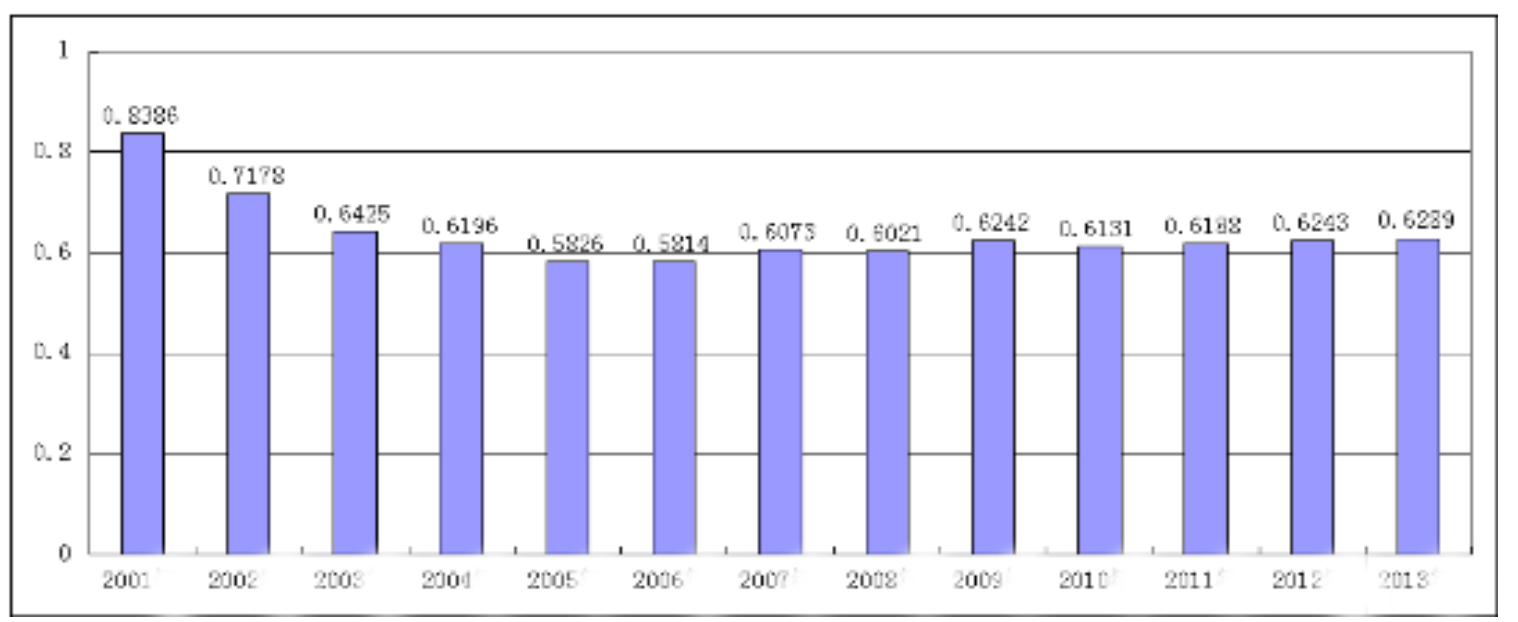

Figure 3. Information industries from 2001 to 2013 in Guangdong province and grey correlation coefficient of main industry

Data sources: Guangdong statistical yearbook 2001-2001.

\subsubsection{Conclusion and Analysis}

It's not hard to see that during 2001-2003 Guangdong province's information technology has a higher associational rate with other industries. The information technology's promotion and driving effect on other industries is remarkable, therefore it reveals the importance of the industry in the whole country-citizen economy system.

\section{Policy Suggestions}

\subsection{To Improve the Level of Information Technology}

China's information technology's general level isn't high. China's made most of the world's computers and mobile phones, though the majorities among them are simply processing products, which requires importing key parts. If China's about to construct the intelligent factory and intelligent manufacturing, the creation of intelligent chips is a must. Therefore, we must independently produce intelligent chips, micro CPUs, and high-speed computers to meet the requirement of intelligent robots, numerical control machines, and intelligent production waterlines. On one hand, we should combine the official production and studying to create a technology innovation league, do researches on the key element parts, and improve China's information technology level in general. On the other hand, we must improve the technology's application and promotion, accelerate the information technology's integration among all industries and promote other industries' development. 


\subsection{Information Industry Infrastructure Construction Lag Behind}

Our country's information technology basic facilities are out of date and unable to satisfy the intelligentized network oriented internet highway. In recent years, our country's internet and mobile networks had developed greatly, but the network construction in the countryside is still outdated, lacking data transition speed and quality and coverage, which severely restrict the information economy's settling and applying. The international electric-information league evaluates that, China's information technology ranks outside of 80 in the world, lacking the exponential type of increment. Meanwhile, because of the information technology level and the operation system, China has a higher internet fee, which also restrict China's mobile internet to develop faster. This is not beneficial to dig out new information economy increment point and the industry's development. Thus, China should accelerate making basic facilities for internet, especially in the countryside, and reforming the internet's operation system, breaking up the monopoly, encouraging competitions, lowering fee level, improving internet speed and service quality.

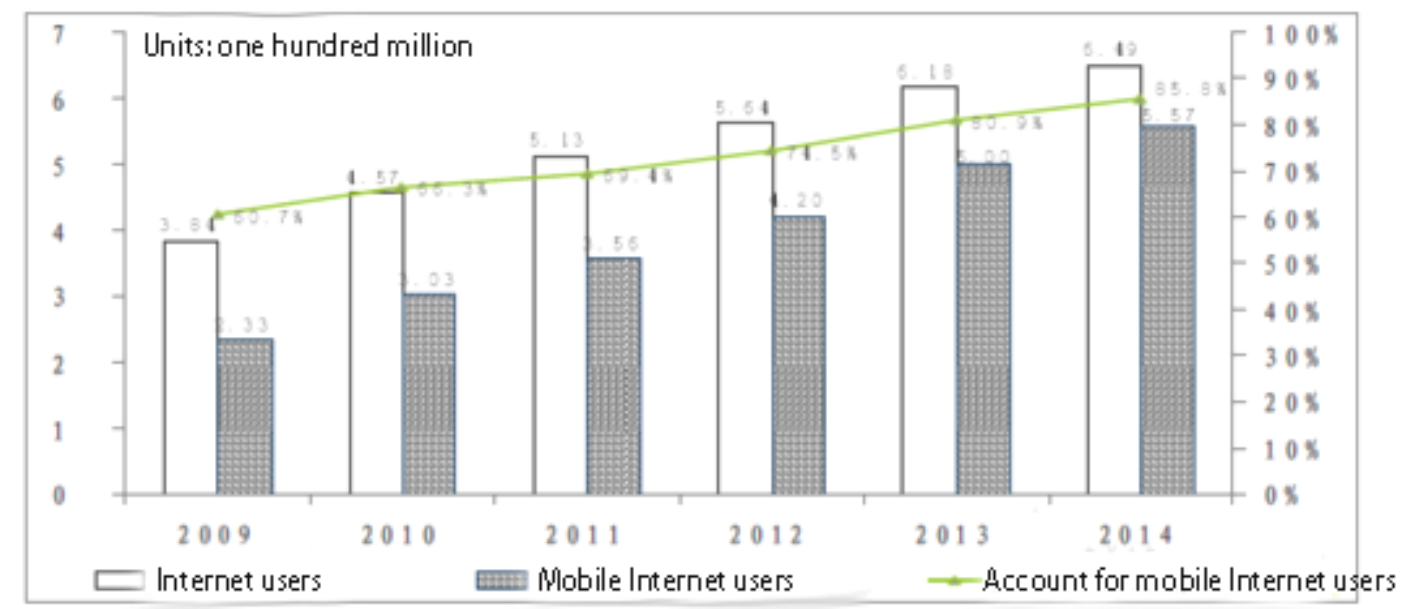

Figure 4. China mobile Internet users from 2012 to 2014 in scale and proportion

Source: CNNIC.

\subsection{Building Intelligent Factory}

Build the intelligent factory and construct Chinese version of industry 4.0. Currently, China's manufacturing industry cost is developing annually. It's become a key issue to accelerate China's manufacturing transformation, cost lowering and competitive power improving. The USA Boston consulting company's report analyze the top 25 economies in world exporting, set the base of 100 for American manufacturing cost, China has the index of 96, which means that when producing the same product, every dollar spent in American manufacturing, 0.96 dollar is spent in Chinese manufacturing. We could that gap has shrunk greatly. This statistic shows that whatever "made in China" costs basically no deferent from what made in America.

There are three main reasons for China's production cost to increase. 1). The RMB exchange rate has gone up, which was a $35 \%$ increment during the decade of 2004 to 2014. 2). China's worker's payment has gone up, which rose from 4.35 dollars per hour in 2004 to 12.47 dollars per hour in 2014, which was a $187 \%$ increment. 3). The energy cost has gone up. China's electricity consume rose from 5.8 dollars per million $\mathrm{Br}$ thermal units to 13.7 dollars per million $\mathrm{Br}$ thermal units, which was a $138 \%$ increment. These costs' going up has given China's manufacturing industry great pressure. From above, we could see that the increment of human resource cost is the main reason for China's production competitive power's decline. It has become essential to lower human resource costs and improves China's competitive power.

We could integrate the information technology with the machines perfectly, forming the intelligent manufacturing. General integration simply just change a few machines' production efficiency, embedded integration could relatively higher increase the equipment's production level. While the information technology and the machines are perfectly integrated, a new industry would be formed, which is the "internett" of things industry. That will greatly promote the manufacturing industry's upgrading and transforming, achieving actual intelligent manufacturing. Currently China has basically constructed the internet of things industry system, forming the IOT 
sense manufacturing, IOT communication and the IOT services. In 2014, the IOT industry scaled over 800 billion yuan, with annual increment of $28 \%$ (graph 5) (De-sheng, 2015). The IOT sense manufacturing is developing rapidly, where sensors, RFIDs could make machine able to recognize the products and instructions; the IOT communication industry, especially the machines to machines network service, makes it possible for machines to work together instead of alone as before; embedded system, software and integration service and other IOT related services have improved the machines' brains and their intelligence. The information technology, IOT technology have made great base for transforming the traditional industries. We should widely use the intelligent robots, automatic machines and intelligent waterline to transform our factories, lower the labor costs, increase production efficiency and reduce energy costs, promote China's manufacturing industry's transformation and upgrading, construct Chinese version of the industry 4.0, rebuilt China's glory.

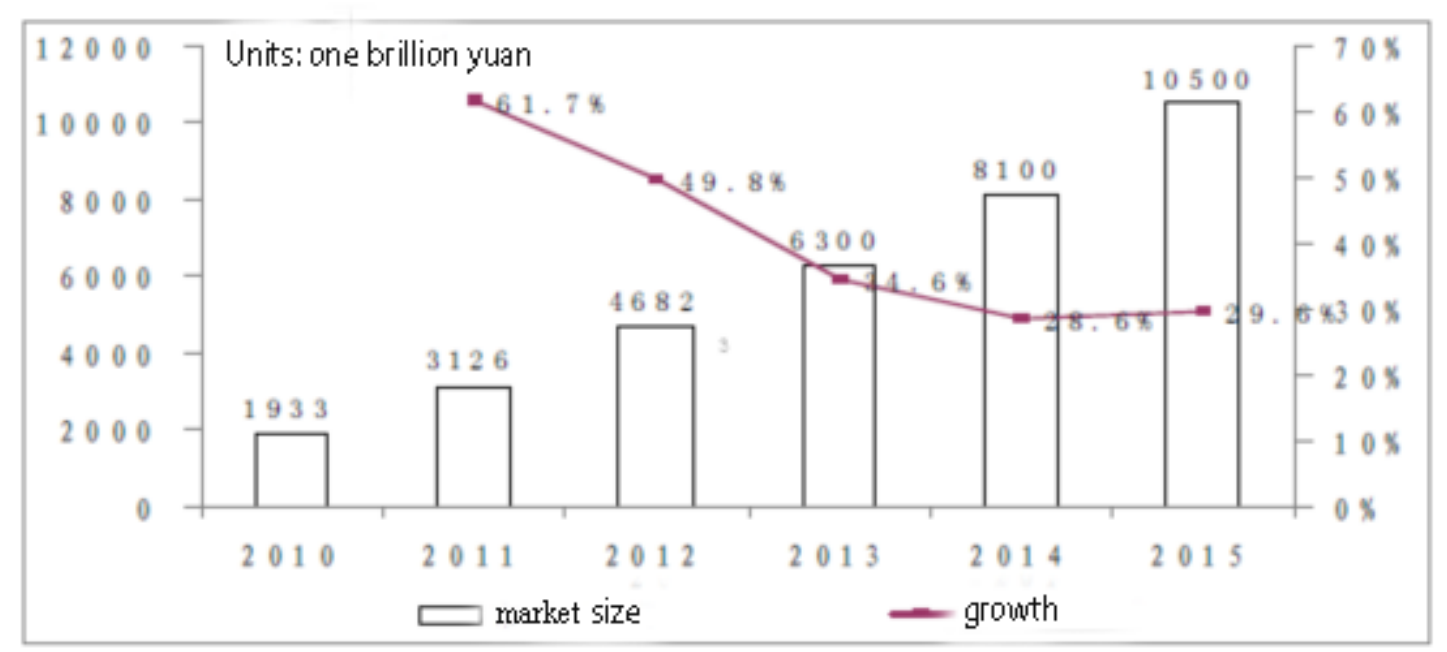

Figure 5. Overall scale of China's internet industry from 2010 to 2015

Source: ministry of industry and information technology institute of electronic science and technology intelligence.

\subsection{Improve Labor Productivity}

Create intelligent production and to increase the industry's labor productivity. The intelligent factory could only solve the problem of a few enterprises, the intelligent production, however, must promote the upgrading and transforming of the whole industry. Today as the production becomes socialized and globalized, if one of the sections is bugged, the whole industry's production would be affected. Therefore, it has become an important issue how to make the whole production balanced and efficient. The intelligent production should cover every section of the industry and value chain and achieve intelligently production operation and control. Operations such as dealing resources, spare parts, automatically containing production supply, reducing storage costs and waste, automatically managing production planning and controlling, checking quality, remaining production safety, packing, storing and delivering products, these could all be intelligently operated according to the market supply and need situations, customers contract and management's direction.

This requires the building of information companies for the whole production process. The networks of the companies, the machines and people are all connected to each other. Intelligentialized, personalized, digitalized with in time sense, dynamic control, unobstructed information, quick reaction, automatic information transition and triggering, this intelligent network must be able to control every section of the production and realize the end to end integration.

\subsection{Enhance the Level of Economic Development}

Creating an intelligent network and improving the whole society's economy in an development level. Take the German intelligent network as an example; it includes the vertical networks of production and products and also the horizontal network of production. The vertical networks of production connect the factory's equipment's production system and the enterprise's sale system. The horizontal networks connect the supplier, producer and the retailer. The vertical networks of the products connect the whole process of the products' design, producing, 
marketing and servicing. To create an intelligent network, the achieving of integrating the whole process of the products' design, producing, marketing and servicing. This network has gone out of the category of purely industry. Only if the production and consuming has been focused can the economy growth continually and the industry 4.0 be achieved.

In recent years, China's e-commerce average annual growth rate is over $20 \%$, on the "double eleven" shopping festival in 2014, in just one site Tmall's turnover reached 57.1 billion yuan, which was the birth of a new world of online retail trade record. In the next 3 to 5 years, with the increasingly perfect communication network and the increasing number of Internet users, China's e-commerce will also sustain average growth of 30\% 30\% (see chart 6) (Lei-xu, 2015).

The rapid development of electronic commerce has greatly improved the efficiency of deals. Ali institute's research shows that online retail trade efficiency is four times as large as entity sales, with every 1 yuan input in the costs, entity retail merchandise is 10.9 yuan, and achievable online retail commodity trading could be up to 49.6 yuan. E-commerce does promote the enterprises' production and improve its economy benefit, accelerate our country's transformation from investment driven to consuming driven, making the whole economy more healthy and robust. Thus, our country needs to put effort into creating intelligent networks and accelerate the whole society's economy transformation.

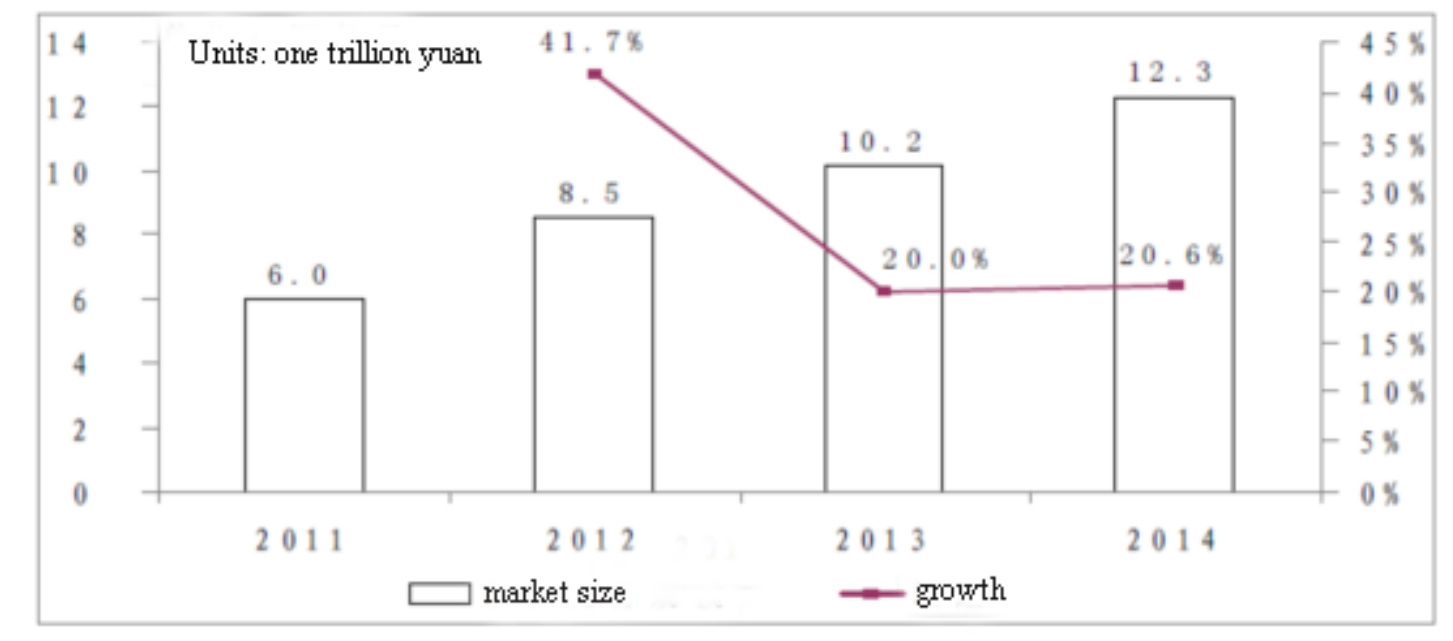

Figure 6. Chinese e-commerce market size of 2011-2011

Source: China electronic commerce research center.

\subsection{To Realize Intelligent Society}

Create smart services, intelligent society. Not only the information industry and industrial integrates, it could also permeate in every aspect of the society, forming new industries, which is called the "internet+". When the "internet+" combines closely with the society's production, distribution, communication and consuming, an intelligent society would come into being and the whole society's development level rises.

Currently "Internet +" stand out for the youth entrepreneurship, business development, corporate finance, as well as education, health care, transportation and other services.

\subsubsection{Aspect of Innovation Service}

The electronic internet collects everyone's intelligence and power and all kinds of information. You could get capital support as long as the innovation is creative, and you could get customers as long as the products are of quality. Customers, crow-funding, crow-sourcing, all kinds of new methods bring endless economic opportunities and innovations to the internet. Relative researches show that the majority of our country's e-commerce is young people under the age of 34, who mostly possess higher educational degrees and a small enterprise under 5 men and has the typical young, knowledge and tiny features. The intelligent networks promote our country's employing and provide great opportunities for everyone's enterprise starting. 


\subsubsection{Enterprise Development Services}

In the enterprise development services, information technology research and development services for the enterprise created a new industry, for example: cloud computing, big data, and so on. This is a perfect combination of information technology. Through the cloud computing, big data, the enterprise can recognize the market information, and develop marketable products. Gartner data show that in 2014, the scale of cloud computing market in China amounted to 52.817 billion yuan, accounting for $5 \%$ of global market share, an increase of $60.4 \%$. China's big data technology matures, is becoming more and more widely applied. Wikibon, according to the 2014 global data industry scale(about $\$ 28.5$ billion), increased by 53\% than that in 2013. Large data size of the market in China is about 8.6 billion yuan, the growth rate of $28.4 \%$, by 2017, will reach 15 billion yuan (see Figure 7) (Lei-xu, 2015). Haier use "air data" development of smart home, genomics companies use big data to construct gene detection and diagnosis technology system, established a large-scale genome sequencing, cloning, crops such as technology platform. Cloud computing, big data has greatly increased the research and development ability of the enterprise.

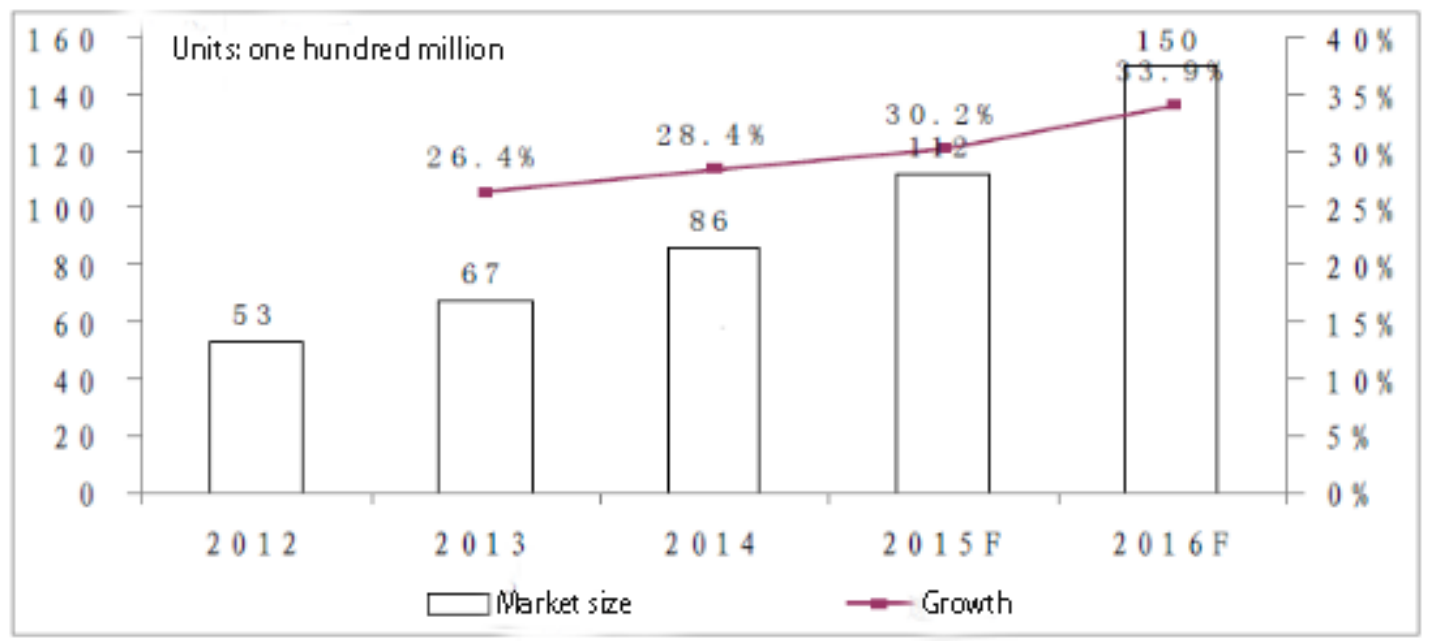

Figure 7. China big data from 2014 to 2016 the size of the market

Source: Ministry of industry and information technology institute of electronic science and technology intelligence.

\subsubsection{Enterprise Financing Services}

Our country's "internet+" economy is also a product of the information technology and economy's high-level integration, and is growing rapidly. Take the "internet+" insurance for example, in 2014 the internet insurance had achieved the income of 85.89 billion yuan, which increased 195\% from last year, and contribute $18.9 \%$ to the whole industry's insurance income increment. Through the "internet+" economy, customers could get access to good inclusive financial services such as the third party payment, online financing and small scale loan. Enterprises could get online insurance, online financing loan and online balancing. Convenient services would promote production and consuming development, adding new energy to the economy transformation. Thus, our country should accelerate making rules and laws for internet economy management in order to protect privacy, internet payment and balancing safety, ensuring financial facilities' capital safety, preventing economy risks and developing the internet economy orderly.

\subsubsection{Internet and Other Industries}

Internet and other industries' integration is transforming other traditional industries on a daily basis. New industries, new production and services methods are emerging. These new things are constantly changing the traditional mindset and breaking the enterprising and producing boundaries. Future enterprises would no longer have to compete just based on their capital depth, enterprise's scale, but their integration quality with the "internet+". For example, the "internet + education" system has broken the common teaching methods of schools and achieved educational resources' social sharing, the "internet + medication" system has broken the region shortage of the hospitals and made it more convenient for citizens to search for medical help, the "Didi taxi" and 
"number one mobile call" have made it possible to call a taxi wherever, whenever as long as there's internet connection. So it's impossible to scale the enterprise since it's everywhere. These are the advantages of modern companies and enterprises. They are transforming enterprises management mindset, enterprise's operations, marketing competition methods every day. Thus, our government, enterprises and the whole society, including ordinary customers, should all actively participate in this "internet+" activity, change our mindset and greatly support the internet to integrate every industry. Only in this way can the "internet+" be able to upgrade every industry and make it into a intelligent society.

\section{Acknowledgements}

The authors acknowledge the project of Grafting, fission and fusion - the strategic study on development pattern and path of emerging industries released by Guangdong Federation of Social Sciences for the "12th five-year plan" (Project number: GD13XYJ07). The project of the college students' innovation and entrepreneurship training plan in Jinan university (national level) (No. 201510559060).

\section{References}

Anonymous. (2013). Industry working group, the federal ministry of education in Germany. German industrial strategic plan implementation suggestion (top) 4.0. Journal of Mechanical Engineering Review, (7-9), 23-33.

Bartelsman, E. J. (2013). ICT, reallocation and productivity. In European Economy-Economic Papers, 2013, No. 486.

Benner, M. J. (2007). The incumbent discount: Stock market categories and response to radical technological change. Academy of Management Review, 32, 703-720. http://dx.doi.org/10.5465/AMR.2007.25275206

Bloom, N., Sadun, R., \& Van Reenen, J. (2012). Americans do I.T. better: US multinationals and the productivity miracle. American Economic Review, 102, 167-201. http://dx.doi.org/10.1257/aer.102.1.167

Brynjolfsson, E., \& Hitt, L. (1996). Paradox lost? Firm-level evidence on the returns to information systems spending. Management Science, 42, 541-558. http://dx.doi.org/10.1287/mnsc.42.4.541

Chuan-zhong, D., \& Zhi-kun, Y. (2015). German industrial 4.0 strategy for transformation and upgrading of China's manufacturing model. Economics and Management Research, (7), 82-87.

De-sheng, L. (2015). Speed up the development of information industry. The New Formats and Macroeconomic Management, (6), 50-57.

Fuxiang, W., \& Lei, Z. (2011). Embedded technology, industry integration and industrial structure transformation effect, based on the six pillar industries in Beijing and Shanghai data of empirical analysis. Shanghai Economic Studies, 2(2), 38-44.

Gârleanu, N., Kogan, L., \& Panageas, S. (2012). Displacement risk and asset returns. Journal of Financial Economics, 105, 491-510. http://dx.doi.org/10.1016/j.jfineco.2012.04.002

Gârleanu, N., Panageas, S., \& Yu, J. (2012). Technological growth and asset pricing. Journal of Finance, 67, 1265-1292. http://dx.doi.org/10.1111/j.1540-6261.2012.01747.x

Grass profit, etc. (1988). The theory of industrial organization (p. 25). Beijing: People's university press.

Greenstein, S., \& Khanna, T. (1997). Competing in the age of digital convergence (pp. 201-226). Boston.

Gruber, F. E. (2013). Industry 4.0: A best practice project of the automotive industry. Digital Product and Process Development Systems, 411, 36-40. http://dx.doi.org/10.1007/978-3-642-41329-2_5

Guo, X. Y., \& Hui, X. F. (2013). Research on Regional Strategic Emerging Industry Selection and Business Model Innovation. Proceedings of 20th International Conference on Industrial Engineering and Engineering Management, Springer Berlin Heidelberg, pp. 643-651. http://dx.doi.org/10.1007/978-3-642-40063-6_64

Hobijn, B., \& Jovanovic, B. (2001). The information technology revolution and the stock market: Evidence. American Economic Review, 91, 1203-1220. http://dx.doi.org/10.1257/aer.91.5.1203

Hu, W. (2006). Theory of market failures of technological innovation and its policy implications. Journal of Dialectics of Nature Research, (10), 63-66.

Hyunbae, C., Jung-Wook, K., \& Jason, L. (2015). How does information technology improve aggregate productivity? A new channel of productivity dispersion and reallocation. Research Policy, 44, 999-1016. http://dx.doi.org/10.1016/j.respol.2014.11.007 
JianNa, S. (2014). Focus on the German industrial 4.0 echoes the two the fusion strategy in China. China Industry News, 2014-10-16.

Ju-long, D. (2005). The basic method of gray system. Huazhong Institute of Technology Press.

Kogan, L., \& Papanikolaou, D. (2013). Firm characteristics and stock returns: The role of investment-specific shocks. Review of Financial Studies, 26, 2718-2759. http://dx.doi.org/10.1093/rfs/hht026

Kogan, L., \& Papanikolaou, D. (2014). Growth opportunities, technology shocks, and asset prices. Journal of Finance, 69, 675-718. http://dx.doi.org/10.1111/jofi.12136

Lasi, H., Fettke, P., \& Kemper, H. G. (2014). Industry 4.0. Business \& Information Systems Engineering, 8(6), 239-242. http://dx.doi.org/10.1007/s12599-014-0334-4

Lei-xu, Z. (2015). The implementation of "Internet +" plan of action, to promote quality upgrade efficiency. Macroeconomic Management, (6), 13-26.

Nie, H., Zhang, Y. B., Chen, J. R. et al. (2015). Research of Chinese Stock Market' Complex Network Structure. International Journal of Economics \& Finance, 7(5), 116-124. http://dx.doi.org/10.5539/ijef.v7n5p116

Oliner, S. D., \& Sichel, D. E. (2000). The resurgence of growth in the late 1990: Is information technology the story?[ Journal of Economic Perspectives, 14, 3-22. http://dx.doi.org/10.1257/jep.14.4.3

Rynjolfsson, E., \& Hitt, L. (2003). Computing productivity: Firm-level evidence. Review of Economics and Statistics, 85, 793-808. http://dx.doi.org/10.1162/003465303772815736

Sailer J. (2014). M2M-the Internet of Things-a Web of Things-4.0. Industry, Elektrotechnik \& Informationstechnik, (2), 3-4. http://dx.doi.org/10.1007/s00502-013-0191-8

Stiroh, K. J. (2002). Information technology and the U.S. productivity revival: What do the industry data say? American Economic Review, 92, 1559-1576. http://dx.doi.org/10.1257/000282802762024638

Voudouris, I., Lioukas, S., \& Iatrelli, M. (2012). Efectiveness of technology investment: Impact of internal technological capability, networking and investment's strategic importance. Technovation, 322(6), 400-414. http://dx.doi.org/10.1016/j.technovation.2012.04.001

Zhen, W. (2015). China's manufacturing costs as the United States, India will become the next "world factory"? China Business Network, the 2015-08-10. Retrievd from http://www.yicai.com/news/2015/08/4667169.html

\section{Copyrights}

Copyright for this article is retained by the author(s), with first publication rights granted to the journal.

This is an open-access article distributed under the terms and conditions of the Creative Commons Attribution license (http://creativecommons.org/licenses/by/3.0/). 